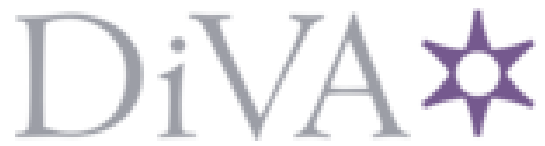

http://www.diva-portal.org

This is the published version of a paper published in Journal of the Electrochemical Society.

Citation for the original published paper (version of record):

Kharitonov, D S., Örnek, C., Claesson, P M., Sommertune, J., Zharskii, I M. et al. (2018)

Corrosion Inhibition of Aluminum Alloy AA6063-T5 by Vanadates: Microstructure

Characterization and Corrosion Analysis

Journal of the Electrochemical Society, 5(3): C116-C126

https://doi.org/10.1149/2.0341803jes

Access to the published version may require subscription.

N.B. When citing this work, cite the original published paper.

Permanent link to this version:

http://urn.kb.se/resolve?urn=urn:nbn:se:ri:diva-34071 


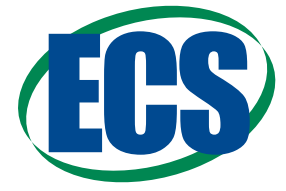

\title{
Corrosion Inhibition of Aluminum Alloy AA6063-T5 by Vanadates: Microstructure Characterization and Corrosion Analysis
}

\author{
Dmitry S. Kharitonov, ${ }^{1,2, *, z}$ Cem Örnek, ${ }^{1,3, * *}$ Per M. Claesson, ${ }^{1,4}$ Jens Sommertune, ${ }^{4}$ \\ Ivan M. Zharskii, ${ }^{2}$ Irina I. Kurilo, ${ }^{5}$ and Jinshan Pan $\circledast^{1, * *, Z}$ \\ ${ }^{I}$ Division of Surface and Corrosion Science, Department of Chemistry, School of Engineering Sciences in Chemistry, \\ Biotechnology and Health, KTH Royal Institute of Technology, SE-100 44 Stockholm, Sweden \\ ${ }^{2}$ Department of Chemistry, Electrochemical Production Technology and Materials for Electronic Equipment, Chemical \\ Technology and Engineering Faculty, Belarusian State Technological University, 220006 Minsk, Belarus \\ ${ }^{3}$ Department of Corrosion in Energy and Process Industry, Swerea KIMAB, SE-164 40 Kista, Sweden \\ ${ }^{4}$ RISE Research Institutes of Sweden, Chemistry, Materials and Surfaces, SE-114 86 Stockholm, Sweden \\ ${ }^{5}$ Department of Physical, Colloid and Analytical Chemistry, Organic Substances Technology Faculty, Belarusian State \\ Technological University, 220006 Minsk, Belarus
}

\begin{abstract}
Corrosion inhibition of aluminum alloy AA6063-T5 by vanadates $\left(\mathrm{NaVO}_{3}\right)$ in $0.05 \mathrm{M} \mathrm{NaCl}$ solution has been investigated by electrochemical and weight loss measurements, and associated with microstructure and Volta potential data. X-ray diffraction, scanning electron microscopy, and energy dispersive spectroscopy analyses confirmed the presence of micrometer-sized Fe-rich $\mathrm{Al}_{4.01} \mathrm{MnSi}_{0.74}, \mathrm{Al}_{1.69} \mathrm{Mg}_{4} \mathrm{Zn}_{2.31}$, and $\mathrm{FeAl}_{3}$ intermetallic phases (IMPs) and nanometer-sized $\mathrm{CuAl}_{2}, \mathrm{ZnAl}_{2}$, and $\mathrm{Mg}_{2}$ Si precipitates in the microstructure. Scanning Kelvin probe force microscopy measurements showed Volta potential differences of up to $600 \mathrm{mV}$ between the microstructure constituents indicating a high susceptibility to micro-galvanic corrosion, with interphase boundary regions exhibiting the highest propensity to corrosion. Most IMPs had cathodic character whereas some nanometer-sized Mg-rich particles exhibited anodic nature, with large Volta potential gradients within interphase regions of large cathodic particles. Electrochemical potentiodynamic polarization measurements indicated that the vanadates provided mixed corrosion inhibition effects, mitigating both oxygen reduction, occurring on cathodic IMPs, and anodic metal dissolution reaction, occurring on anodic sites, such as $\mathrm{Mg}_{2} \mathrm{Si}$ and interphase boundary regions. Electrochemical measurements indicated that the sodium metavanadate inhibitor blocks active metal dissolution, giving high inhibition efficiency ( $>95 \%$ ) during the initial exposure, whereas long-term weight loss measurements showed that the efficacy decreases after prolonged exposure.

(C) The Author(s) 2018. Published by ECS. This is an open access article distributed under the terms of the Creative Commons Attribution Non-Commercial No Derivatives 4.0 License (CC BY-NC-ND, http://creativecommons.org/licenses/by-nc-nd/4.0/), which permits non-commercial reuse, distribution, and reproduction in any medium, provided the original work is not changed in any way and is properly cited. For permission for commercial reuse, please email: oa@electrochem.org. [DOI: 10.1149/2.0341803jes]
\end{abstract}

(cc) BY-NC-ND

Manuscript submitted November 2, 2017; revised manuscript received February 6, 2018. Published February 14, 2018.

Aluminum and its alloys are attractive materials for a range of industrial applications due to cost-efficient recyclability, excellent physical and mechanical properties, such as low density, high thermal conductivity, good weldability, and high strength-to-weight ratio. ${ }^{1-4}$ In particular, the $6 \mathrm{xxx}$-series $(\mathrm{Al}-\mathrm{Mg}-\mathrm{Si}$ ) alloys are widely used in aerospace, automotive, marine, and construction industries due to their relatively good corrosion resistance, formability, and low cost as compared to the $2 \mathrm{xxx}(\mathrm{Al}-\mathrm{Cu})$ and $7 \mathrm{xxx}(\mathrm{Al}-\mathrm{Zn})$ alloys. ${ }^{5-7}$ However, these alloys contain multiple alloying elements and their microstructure is very heterogeneous, typically consisting of a large variety of intermetallic phases (IMPs), which makes them highly susceptible to localized corrosion such as pitting or intergranular corrosion. ${ }^{5,8,9}$ While nanometer-sized IMPs, dispersed in the Al matrix, are desirable for mechanical strength of Al alloys, micrometer-sized IMPs may induce localized corrosion due to micro-galvanic coupling between the Al matrix and the IMPs, ${ }^{10-12}$ which may also affect the anodization process. ${ }^{13,14}$ IMPs play an important role in localized corrosion since their type, size, and distribution can affect electrochemical reactions, homogeneous chemical reactions as well as transport phenomena of molecular and ionic species. ${ }^{8,15,16}$ Therefore, detailed knowledge about IMPs in the Al alloy is needed when exploring the mechanism of corrosion and its inhibition.

For a number of decades, chromate-based inhibitors, pigments, and conversion coatings, have been extensively used for corrosion protection of $\mathrm{Al}$ alloys. ${ }^{17,18}$ However, nowadays the use of $\mathrm{Cr}(\mathrm{VI})$ compounds has been strongly restricted due to their carcinogenicity, mutagenicity, and toxicity, ${ }_{18}$ and some alternative schemes for corrosion protection have been reported. ${ }^{19,20}$ In recent studies, chromatelike oxyanion inhibitors and conversion coatings, such as molybdates,

\footnotetext{
*Electrochemical Society Student Member.

**Electrochemical Society Member

zE-mail: kharitonov@belstu.by; dz@kth.se; jinshanp@kth.se
}

permanganates, tungstates, and vanadates have shown promising results in the corrosion suppression of steel, $\mathrm{Zn}, \mathrm{Al}$ and $\mathrm{Mg}$ alloys. ${ }^{9,21-26}$ Special attention has been given to vanadates due to their high inhibition efficiency and usability. ${ }^{25,27-36}$ Corrosion inhibition by soluble vanadates have been studied in detail for alloy AA2024 by Frankel et al., and Buchheit et al., ${ }^{25,30-33}$ who showed that the inhibition effectiveness of vanadates is strongly related to the microstructure. Furthermore, it has been reported that vanadates inhibit cathodic reactions in aerated solutions by suppression of the oxygen reduction reaction on the surface of $S$-phase $\left(\mathrm{Al}_{2} \mathrm{MgCu}\right)$ IMPs. ${ }^{25,32}$ Recently, Hurley et al. found high selectivity of vanadates to form polymerized species above $\mathrm{Cu}_{2} \mathrm{O}$, whereas monomeric vanadate species were seen above $\mathrm{Al}$ oxide. The presence of both $\mathrm{V}^{+5}$ and $\mathrm{V}^{+4}$ species in adsorbed films was confirmed by X-ray Photoelectron Spectroscopy (XPS). Vanadate species were proposed to have reduced from +5 to +4 oxidation state above $\mathrm{Cu}$-rich IMPs. ${ }^{28,33}$ Despite considerable information on inhibition efficiency for the high-copper AA2024 alloy, only few papers focused on the usage of vanadates as corrosion inhibitors for other $\mathrm{Al}$ alloys. ${ }^{36-40}$ Recently, vanadates have been shown to decrease the overall corrosion rate of alloy AA6061. ${ }^{36}$

Alloy AA6063-T5, investigated in this study, has a copper content of $0.1 \mathrm{wt} \%$, which is low as compared to $4.5 \mathrm{wt} \%$ for AA2024. Different copper contents could lead to differences in the mechanism and efficiency of corrosion inhibition by vanadates. ${ }^{36}$ Generally, a wide range of IMPs are formed in commercial 6xxx-series Al alloys during solidification and thermomechanical processing. ${ }^{41,42}$ Typical IMPs are Fe-rich $\beta-\mathrm{Al}_{5} \mathrm{FeSi}, \alpha-\mathrm{Al}_{12} \mathrm{Fe}_{3} \mathrm{Si}, \mathrm{Al}_{x}(\mathrm{FeMn})_{3} \mathrm{Si}$, which exhibit a cathodic character as compared to the matrix. ${ }^{43}$ Smaller $\mathrm{Mg}_{2} \mathrm{Si}$ precipitates are also common in the microstructure and their electrochemical behavior depends on the surface elemental termination and oxide film. It has been reported, ${ }^{5,14,42,43}$ that $\mathrm{Mg}_{2} \mathrm{Si}$ may reverse from anodic to cathodic behavior due to de-alloying of $\mathrm{Mg}$ and formation of Si-rich surface areas. ${ }^{714}$ However, the exact composition of the IMPs 
Table I. Chemical composition (wt\%) of aluminum alloy AA6063-T5.

\begin{tabular}{cccccccccc}
$\mathrm{Si}$ & $\mathrm{Fe}$ & $\mathrm{Cu}$ & $\mathrm{Mn}$ & $\mathrm{Mg}$ & $\mathrm{Cr}$ & $\mathrm{Zn}$ & $\mathrm{Ti}$ & Others & $\mathrm{Al}$ \\
\hline 0.45 & 0.50 & 0.10 & 0.10 & 0.60 & 0.10 & 0.20 & 0.15 & $<0.15$ & Bal.
\end{tabular}

is influenced by the composition of the alloy and its thermomechanical processing history.

In this paper we focus on microstructure characterization of the AA6063-T5 alloy and related local Volta potential assessments, and demonstrate the effectiveness of sodium vanadate for mitigating corrosion of AA6063-T5 in chloride-containing medium by electrochemical and weight loss measurements. Detailed in-situ confocal Raman analyses will be reported elsewhere.

\section{Experimental}

Materials and sample preparation.-Aluminum alloy AA6063T5, supplied as an extruded plate material by Taspo Radiators (Minsk, Belarus), was used in this study. The nominal chemical composition, as provided by the supplier, is given in Table I. Coupon specimens of sizes $20 \mathrm{~mm} \times 20 \mathrm{~mm} \times 2.5 \mathrm{~mm}$ and $10 \mathrm{~mm} \times 10 \mathrm{~mm} \times 2.5 \mathrm{~mm}$ were cut from the plate material in normal direction and mechanically ground to 1200 -grit using $\mathrm{SiC}$ sandpapers. For microstructure analysis, samples were further ground to 4000 -grit and polished to $0.25 \mu \mathrm{m}$ diamond paste using $99.9 \%$ alcohol as lubricant. A final end-polishing for 20 minutes using an active silica oxide suspension (OP-S) from Struers was done to remove surface strain from grinding and polishing and to obtain grain orientation contrast. The microstructure was further investigated on a coupon specimen which was ground to 1200-grit and then electropolished using a mixture of $20 \mathrm{vol} .-\%$ perchloric acid and 80 vol.- $\%$ ethanol at $20 \mathrm{~V}$ and $-15^{\circ} \mathrm{C}$ for 30 seconds. Electropolishing was done to preserve nanometer-sized particles on the surface, which typically fall out during mechanical polishing.

Microstructure characterization.-Microstructure characterization included X-ray diffraction (XRD), scanning electron microscopy (SEM), energy-dispersive X-ray spectroscopy (EDX), and SKPFM measurements.

$X R D$ measurement. - XRD measurements were performed on an OP-S end-polished specimen using a Bruker Discover D8 diffractometer. A cobalt $\left(\lambda_{\mathrm{K} \alpha 1}=1.788965 \mathrm{~nm}\right)$ cathode ray tube was used with a tube voltage of $40 \mathrm{kV}$ and a tube current of $40 \mathrm{~mA}$. A step size of $0.01^{\circ}$ with 7 seconds dwelling time at each step was used to obtain high-resolution diffraction data. The $2 \theta$ scan range was $20-120^{\circ}$. The data was processed using the OriginPro 2017 software and smoothed by the Savitzky-Golay filtering method with 20 points per window and a polynomial order of 5 . The $2^{\text {nd }}$ derivative method was used to find the peaks. Phase identification was done by a manual search-match procedure. Powder diffraction file (PDF) reference cards of possible phases were obtained from the International Centre for Diffraction Data (ICDD), and their peak positions and intensities were compared with those observed experimentally.

SEM and EDX analyses. - SEM and EDX analyses were performed on both OP-S polished and electropolished samples using a JEOL JSM-7001F SEM, equipped with the Oxford Instruments XMax EDX Silicon Drift Detector with $80 \mathrm{~mm}^{2}$ window size. EDX maps were recorded at 3.5-10 kV accelerating voltage and high probe current over tens of minutes to obtain high spatial resolution using AZtec V3.3 acquisition software. At least ten maps over different areas were obtained. Point analyses were carried out at $10-15 \mathrm{kV}$ to obtain quantitative chemical composition of large IMPs.

Volta potential measurements.-Scanning Kelvin Probe Force Microscopy (SKPFM) measurements were carried out on the OP-S polished specimen using a Bruker Icon atomic force microscope in amplitude modulation (AM) and frequency modulation (FM) mode to measure the local Volta potential difference of the microstructure.
AM-SKPFM is less sensitive to topographical artefacts and was therefore used to map larger areas $(50 \mu \mathrm{m} \times 50 \mu \mathrm{m})$, whereas FM-SKPFM allows mapping with higher spatial resolution of both topography and potential. Therefore, FM-SKPFM was used to map smaller regions $(5 \mu \mathrm{m} \times 5 \mu \mathrm{m})$ in order to characterize nanometer-sized IMPs. Ptcoated AFM probes OSCM-PT from Olympus were used, and the images were obtained with a scan rate of $0.2-0.5 \mathrm{~Hz}$ and $256 \times$ 256 pixels. The drive amplitude was $2.6-3.3 \mathrm{~V}$, which was chosen depending on the region of interest. In all measurements, the bias potential, $6 \mathrm{~V}$, was applied to the tip whereas the sample was grounded. AM-SKPFM measurements were performed via a two-pass procedure which measures the topography at the first scan line, then the tip is lifted to a user pre-defined height (here $50 \mathrm{~nm}$ ), and then the potential is measured following the recorded topography. FM-SKPFM measurements were performed in single-pass mode, which allows simultaneous recording of both topography and potential. Three different locations of the same specimen were scanned in duplicate to ensure data reliability. All measurements were carried out at lab environment (ca. $21^{\circ} \mathrm{C}$ and $40 \%$ relative humidity). The data was processed using Nanoscope V1.5 software (Bruker) and plotted as 2D topography and potential maps. The topography maps were flattened using $1^{\text {st }}$ flattening order and no filter was applied. The Volta potential maps were not flattened and show absolute potential differences with respect to platinum. Interpretation of Volta potential data was in line with previous works for steel and $\mathrm{Al}$ alloys. ${ }^{44-50}$ The Volta potential images were inverted to conform to the electrochemical nobility convention (sample bias condition). Thus, higher Volta potentials indicate a cathodic character, whereas lower potentials indicate an anodic nature. ${ }^{51}$ A potential difference between anodic and cathodic sites would indicate a driving force for micro-galvanic activity and is a sign for the susceptibility to localized corrosion.

Corrosion measurements.-The efficiency of corrosion protection by vanadates was evaluated by both electrochemical measurements that yield the corrosion rate at the time of the measurement, and weight loss measurements at different time intervals that give average values of the corrosion rate over the periods of time for each interval. All solutions were prepared with $18.2 \mathrm{M} \Omega$-cm deionized water (Milli-Q system) and analytical grade $\mathrm{NaVO}_{3}(\geq 98 \%$, Sigma-Aldrich Germany) and $\mathrm{NaCl}(\geq 99 \%$, Sigma-Aldrich USA). The corrosion experiments were performed in aqueous $0.05 \mathrm{M} \mathrm{NaCl}$ and $0.05 \mathrm{M} \mathrm{NaCl}$ $+3 \mathrm{mM} \mathrm{NaVO}_{3}$ solutions, respectively. This inhibitor concentration, $3 \mathrm{mM}$, was chosen based on previous studies, ${ }^{25,28,36}$ showing good corrosion inhibition over a wide $\mathrm{pH}$ range. The measured $\mathrm{pH}$ of the as-prepared solutions was 6.5-6.7, and after 24 hours of exposure the $\mathrm{pH}$ value decreased to ca. 6 . The as-prepared $3 \mathrm{mM} \mathrm{NaVO}_{3}$ solution was colorless with $\mathrm{pH}$ 7.2. It has been reported that tetrahedrally coordinated anions are dominating vanadium species in such solutions. ${ }^{25,36}$ The solutions were used without $\mathrm{pH}$ adjustment.

Weight loss measurements were carried out in time lapse up to 1000 hours at $25 \pm 1{ }^{\circ} \mathrm{C}$ in a temperature-controlled TC-80M-2 (Medlabtechnika, Russia) cabinet. The exposed surface area of all samples was $5 \mathrm{~cm}^{2}$ and a ratio of $100 \mathrm{~cm}^{3}$ of solution per $1 \mathrm{~cm}^{2}$ of exposed metal surface area was used for the measurements. The samples were taken out from the solutions in discrete time intervals, wiped with a paper tissue, immersed in $20 \% \mathrm{HNO}_{3}$ for 1 minute to remove formed corrosion products, rinsed by deionized water, and placed in a desiccator to fully dry the specimen. This procedure was seen to remove corrosion products without attacking the metal, being in accordance with the standard practice ISO 8407:2009.52,53 The samples were then weighed with $0.1 \mathrm{mg}$ accuracy using a microbalance. All weight loss measurements were replicated on 10 parallel samples.

Electrochemical measurements consisted of potentiodynamic polarization scans and electrochemical impedance spectroscopy (EIS), which were performed on specimens exposed to aqueous $0.05 \mathrm{M}$ $\mathrm{NaCl}$ solution with and without $3 \mathrm{mM} \mathrm{NaVO}_{3}$ for 1 and 24 hours, respectively. The Autolab PGSTAT128N instrument from Metrohm Autolab B.V. and a standard three-electrode electrochemical cell setup with a saturated $\mathrm{Ag} / \mathrm{AgCl}$ reference electrode and a Pt-mesh counter 

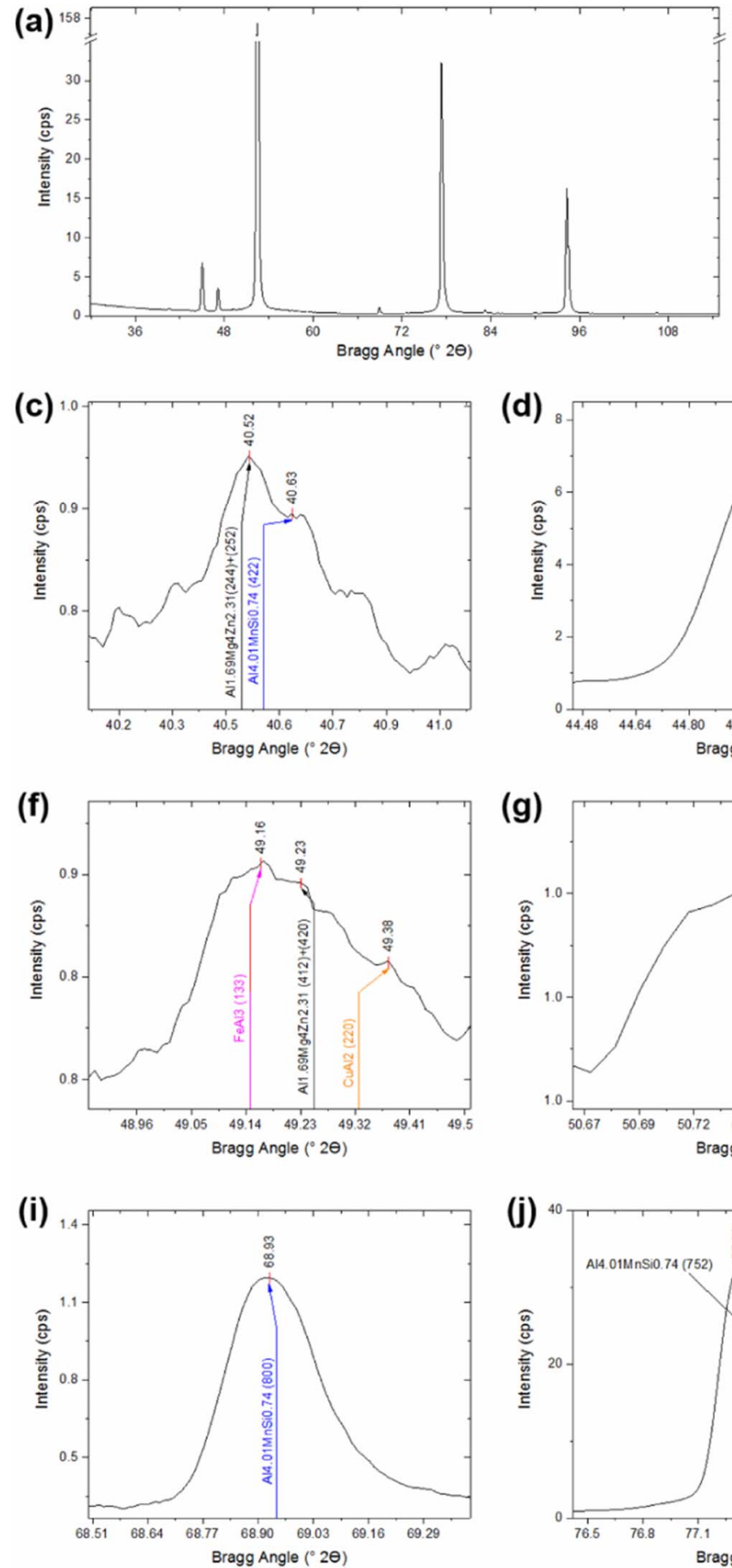
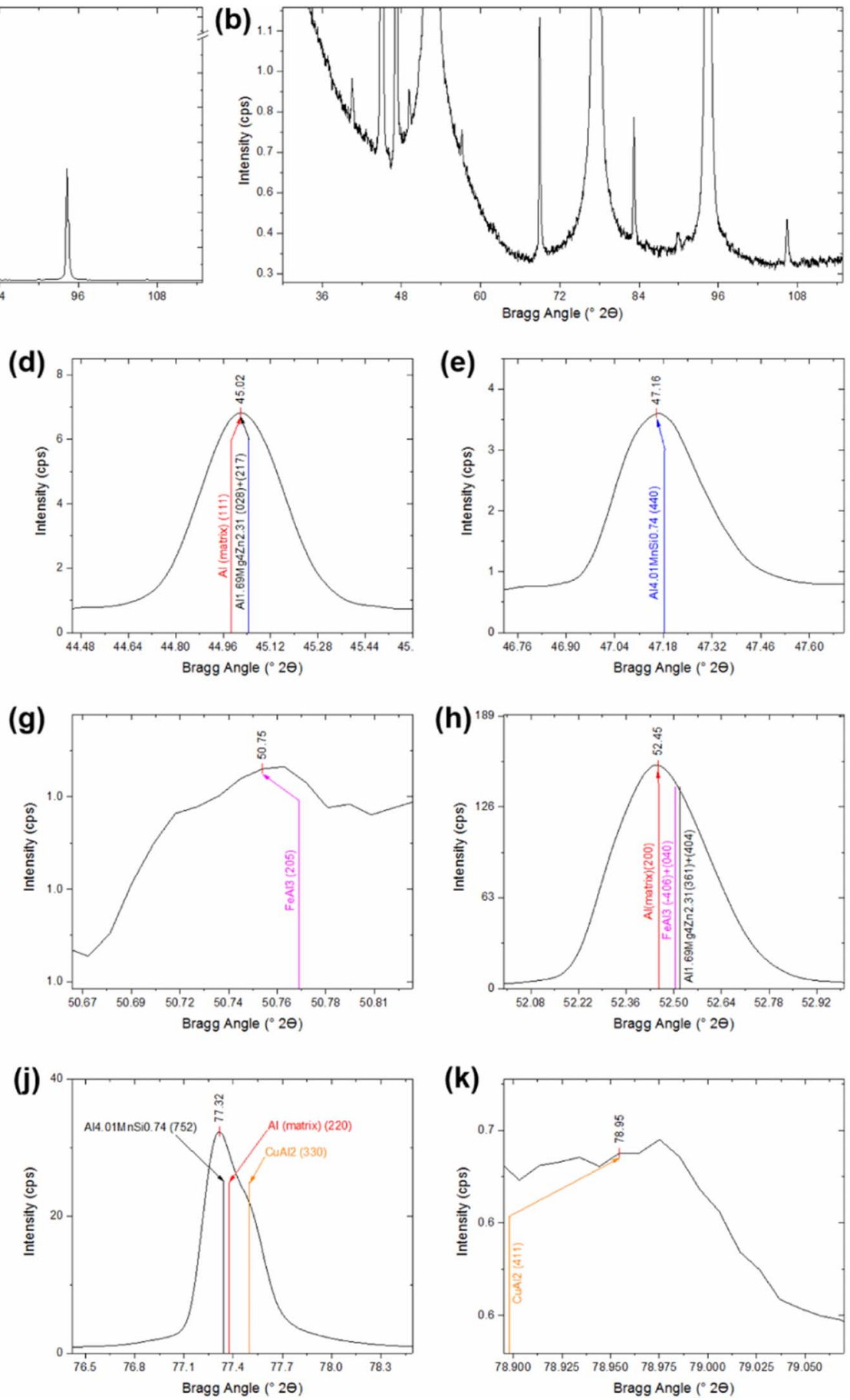

Figure 1. (a) XRD diffractogram of alloy AA6063-T5 showing all detected peaks with corresponding phases and their crystallographic orientation, (b) magnified view showing small peaks, (c-k) some selected peaks of indexed phases.

electrode were used for both polarization and EIS tests. The exposed area of the sample was $1 \mathrm{~cm}^{2}$. All measurements were performed at room temperature $\left(\approx 21^{\circ} \mathrm{C}\right)$ and replicated at least three times.

Potentiodynamic polarization scans were made within the potential range from $-200 \mathrm{mV}$ to $+200 \mathrm{mV}$ vs. the open-circuit potential (OCP) at a scan rate of $0.5 \mathrm{mV} / \mathrm{s}$. Electrochemical parameters were extracted from polarization curves using the Levenburg-Marquardt method in Corrview 2 software. EIS measurements were carried out at OCP over the frequency range from $10^{4}$ to $10^{-2} \mathrm{~Hz}$ using perturbation amplitude of a $10 \mathrm{mV}$. The ZView 3.2 and Nova 1.11 software were used for data analysis and spectra fitting.

\section{Results and Discussion}

XRD analysis. - The obtained diffractogram of alloy AA6063-T5 is shown in Figures 1a, 1b, and some selected peaks of indexed phases are shown in Figures 1c-1k. At least 21 distinctive peaks with different signal intensities were detected. The peak positions with their relative intensities have been compared against the library references and assigned to the phase with the best peak-to-peak fit. In this manner, $\mathrm{Al}_{4.01} \mathrm{MnSi}_{0.74}, \mathrm{Al}_{1.69} \mathrm{Mg}_{4} \mathrm{Zn}_{2.31}, \mathrm{FeAl}_{3}, \mathrm{CuAl}_{2}$, and $\mathrm{Al}$ were indexed. All indexed peaks with suggested phases are listed in Table II. From all searched peak positions, $\mathrm{Al}_{4.01} \mathrm{MnSi}_{0.74}$ matched with eleven reflectors 


\begin{tabular}{|c|c|c|c|c|}
\hline Peak No. & $2 \theta$ Peak Position & Suggested Phase & Plane & $2 \theta$ \\
\hline \multirow[t]{2}{*}{1} & 40.521 & $\mathrm{Al}_{1.69} \mathrm{Mg}_{4} \mathrm{Zn}_{2.31}$ & 244 & 40.50 \\
\hline & & & 252 & 40.50 \\
\hline 2 & 40.634 & $\mathrm{Al}_{4.01} \mathrm{MnSi}_{0.74}$ & 422 & 40.55 \\
\hline \multirow[t]{3}{*}{3} & 45.019 & $\mathrm{Al}$ (matrix) & 111 & 44.98 \\
\hline & & $\mathrm{Al}_{1.69} \mathrm{Mg}_{4} \mathrm{Zn}_{2.31}$ & 028 & 45.04 \\
\hline & & & 217 & 45.04 \\
\hline 4 & 47.161 & $\mathrm{Al}_{4.01} \mathrm{MnSi}_{0.74}$ & 440 & 47.18 \\
\hline 5 & 49.164 & $\mathrm{FeAl}_{3}$ & 133 & 49.14 \\
\hline \multirow[t]{2}{*}{6} & 49.230 & $\mathrm{Al}_{1.69} \mathrm{Mg}_{4} \mathrm{Zn}_{2.31}$ & 412 & 49.25 \\
\hline & & & 420 & 49.25 \\
\hline 7 & 49.375 & $\mathrm{CuAl}_{2}$ & 220 & 49.32 \\
\hline 8 & 50.754 & $\mathrm{FeAl}_{3}$ & 205 & 50.77 \\
\hline \multirow[t]{5}{*}{9} & 52.453 & $\mathrm{Al}$ (matrix) & 200 & 52.45 \\
\hline & & $\mathrm{FeAl}_{3}$ & -406 & 52.50 \\
\hline & & & 040 & 52.50 \\
\hline & & $\mathrm{Al}_{1.69} \mathrm{Mg}_{4} \mathrm{Zn}_{2.31}$ & 361 & 52.51 \\
\hline & & & 404 & 52.51 \\
\hline 10 & 57.005 & $\mathrm{FeAl}_{3}$ & 315 & 57.07 \\
\hline 11 & 57.343 & $\mathrm{Al}_{4.01} \mathrm{MnSi}_{0.74}$ & 631 & 57.35 \\
\hline 12 & 57.385 & $\mathrm{Al}_{1.69} \mathrm{Mg}_{4} \mathrm{Zn}_{2.31}$ & $\begin{array}{l}282 \\
370\end{array}$ & 57.39 \\
\hline 13 & 68.926 & $\mathrm{Al}_{4.01} \mathrm{MnSi}_{0.74}$ & 800 & 68.94 \\
\hline \multirow[t]{3}{*}{14} & 77.317 & $\mathrm{Al}_{4.01} \mathrm{MnSi}_{0.74}$ & 752 & 77.34 \\
\hline & & $\mathrm{Al}$ (matrix) & 220 & 77.37 \\
\hline & & $\mathrm{CuAl}_{2}$ & 330 & 77.50 \\
\hline 15 & 78.955 & $\mathrm{CuAl}_{2}$ & 411 & 78.89 \\
\hline 16 & 83.217 & $\mathrm{Al}_{4.01} \mathrm{MnSi}_{0.74}$ & 664 & 83.16 \\
\hline 17 & 89.948 & $\mathrm{Al}_{4.01} \mathrm{MnSi}_{0.74}$ & 358 & 89.91 \\
\hline \multirow[t]{2}{*}{18} & 94.296 & $\mathrm{Al}_{4.01} \mathrm{MnSi}_{0.74}$ & 951 & 94.08 \\
\hline & & $\mathrm{Al}$ (matrix) & 311 & 94.20 \\
\hline \multirow[t]{2}{*}{19} & 94.532 & $\mathrm{CuAl}_{2}$ & 004 & 94.51 \\
\hline & & $\mathrm{Al}_{4.01} \mathrm{MnSi}_{0.74}$ & 1022 & 94.65 \\
\hline 20 & 106.369 & $\mathrm{Al}_{4.01} \mathrm{MnSi}_{0.74}$ & 880 & 106.34 \\
\hline 21 & 106.802 & $\mathrm{Al}_{4.01} \mathrm{MnSi}_{0.74}$ & 2510 & 106.94 \\
\hline
\end{tabular}

and $\mathrm{Al}_{1.69} \mathrm{Mg}_{4} \mathrm{Zn}_{2.31}$ with ten reflectors. Furthermore, $\mathrm{FeAl}_{3}$ matched with five peaks and $\mathrm{CuAl}_{2}$ matched with four peaks, respectively (Table II). The Al matrix generated five peaks. Many peaks of the suggested phases had similar Bragg angles, which caused irregular shapes of some peaks. It should be noted that the exact composition of these phases could slightly vary, resulting in minor variations of the reported phase stoichiometry. For instance, $\mathrm{Al}_{4.01} \mathrm{MnSi}_{0.74}$ should, therefore, be considered as an Al-Mn-Si-rich type of IMP with perhaps some other alloying elements. This also applies for the other phases reported.

In general, three fits are required for phase identification in an alloy. However, to unambiguously identify three peaks may not always be possible for intermetallic particles with low fractions and small sizes. The Al alloy used in our study was extruded and therefore had nonequiaxed and textured grains along the extrusion direction. Moreover, the IMPs were also textured which may have resulted in less diffraction with lower intensities. Intermetallic phases, such as $\mathrm{Mg}_{2} \mathrm{Si}, \mathrm{ZnAl}_{2}$, and $\mathrm{MgZn}_{2}$ were expected but not detected by the XRD analysis. However, $\mathrm{Mg}_{2} \mathrm{Si}$ and possibly $\mathrm{ZnAl}_{2}$ were observed with other analysis methods as reported below. Together this suggests that a very minor fraction of $\mathrm{Mg}_{2} \mathrm{Si}$ and possibly also some $\mathrm{ZnAl}_{2}$ were present, but below the detection limit of the XRD instrument.

SEM/EDX analyses.-A general view of the microstructure of AA6063-T5 after OP-S polishing and electropolishing is shown in Figure 2 and Figure 3, respectively. Electropolishing seemed to preserve nanometer-sized IMP on the surface, whereas during mechanical polishing most of these particles fell off. These particles seemed to be incoherent to the Al matrix and were often arrayed in conglomerated clusters, indicating stronger coherency to the IMPs of the same kind than to the matrix (Figure 3c). These particles were heterogeneously dispersed and had globular shapes. However, in both cases numerous intermetallic particles were observed in the microstructure, visible as bright areas in the SEM images. Intermetallic particles were located at both inter- and intra-granular sites and distributed in the microstructure. The size of the larger IMPs varied between 3-10 $\mu \mathrm{m}$ and had an abundance of tens of particles per grain (Figure 2 and Figure 3). In contrast, sub-micrometer-sized IMPs had $<400 \mathrm{~nm}$ sizes with an estimated particle density of hundreds of particles per grain (Figures $3 \mathrm{~b}, 3 \mathrm{c}$ ). The large particles did not seem to be influenced by the polishing treatment. The fine-scaled IMPs present in the microstructure (Figure 2c) were more coherent to the matrix than the clustered particles and did not seem to have conglomerated. It remained unclear whether these are of different nature.

EDX analyses confirmed the presence of all alloying elements in the microstructure. In addition, a strong peak for the L-lines of silver was detected. The alloy was produced from recycled material, and it is likely that some minor impurities remained in the microstructure. EDX map was obtained from a site containing large precipitates (Figure 4). There seemed to be two or three different phases next to each other with different compositions, as labelled in the $\mathrm{Al} \mathrm{K} \alpha$ map in Figure 4. In $\mathrm{Al}$ alloys, phases can co-nucleate and support further nucleation by providing free surface energies at interface regions, and this appears to be the case here. ${ }^{54}$

Phase 1 (Figure 4) was mainly enriched in $\mathrm{Si}, \mathrm{Fe}, \mathrm{Mn}, \mathrm{Cr}$, with some $\mathrm{Al}, \mathrm{Cu}, \mathrm{Zn}, \mathrm{Mo}$, and $\mathrm{Mg}$. The chemical composition and morphology suggested this to be a Fe-rich Al-Mn-Si phase with some other elements. The majority of all EDX maps showed these elements and, hence, taking the size and shape into consideration, this phase was most likely an $\mathrm{Al}_{4.01} \mathrm{MnSi}_{0.74}$-type of precipitate. In contrast, phase 2 was mainly enriched in $\mathrm{Cu}$ and $\mathrm{Fe}$, with some $\mathrm{Zn}, \mathrm{Mn}$, and $\mathrm{Cr}$, suggesting this as a $\mathrm{CuAl}_{2}$-type of intermetallic phase. Phase 2 appears to have nucleated between two Fe-rich $\mathrm{Al}-\mathrm{Mn}-\mathrm{Si}$ intermetallic particles. Phase 3 had similar composition to phase 2 . There was only some Mg enriched in phase 3, which was not observed in phase 2. This example illustrates the complex nature of the precipitation phenomena in this alloy, which is due to macro- and micro-segregation of metal
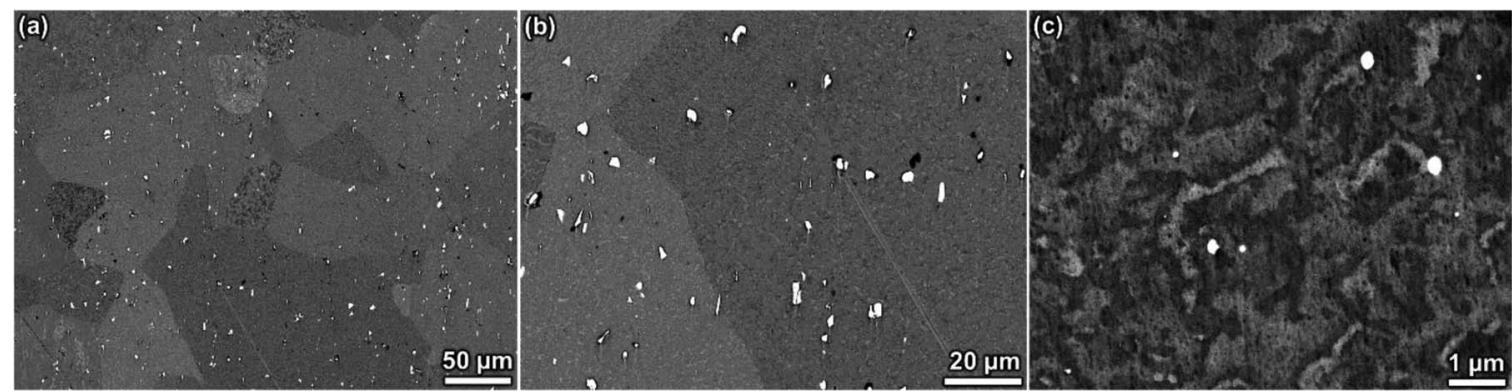

Figure 2. BSE-SEM images showing the microstructure of alloy AA6063-T5 (OP-S end-polished): Intermetallic phases and dispersoids of different sizes are visible (bright dots), distributed homogeneously in the microstructure. 

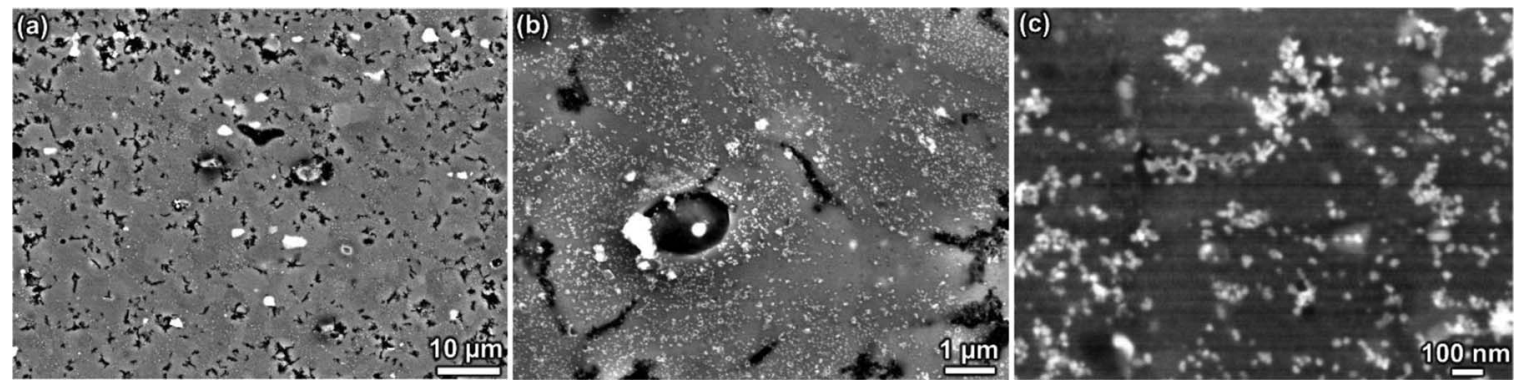

Figure 3. Microstructure of AA6063-T5 alloy (electropolished): (a) BSE-SEM image showing a general overview of the microstructure, (b) SE-SEM image showing numerous nanometer-sized precipitates with some micrometer-sized IMPs, (c) BSE-SEM image showing nanometer-sized precipitates at higher resolution.

elements with low melting points whose phase diagram show two- or more-phase mixture regions. ${ }^{55}$

Further EDX analyses were performed on the electropolished sample, containing IMPs with different shapes and varying sizes (Figure 5). An irregularly-shaped precipitate, rich in $\mathrm{Mg}, \mathrm{Si}, \mathrm{Cr}$, and $\mathrm{Ti}$, was detected. Further, globular particles, rich in mainly $\mathrm{Fe}$ and $\mathrm{Mn}$, were observed. Some $\mathrm{Cu}-\mathrm{Cr}$-Si-rich nanometer-sized particles were also detected. The large particles contained $\mathrm{Al}, \mathrm{Mg}, \mathrm{Zn}, \mathrm{Ti}$, and $\mathrm{Cr}$, suggesting that these are of $\mathrm{Al}_{1.69} \mathrm{Mg}_{4} \mathrm{Zn}_{2.31}$-type. SEM imaging in BSE mode (sampling depth of hundreds of nm) revealed a few micrometer-sized precipitates, which could not be seen in the SE images (Figure 5) due to lower sampling depth in the SE mode (a few $\mathrm{nm}$ ). These were enriched in Fe suggesting that they were of the $\mathrm{FeAl}_{3}$-type.

High-resolution EDX mapping was also performed on a region containing a dense distribution of precipitates (Figure 6). The large particle in the center of the image (dark contrast) was rich in $\mathrm{Mg}$ and $\mathrm{Si}$. A globular particle, containing $\mathrm{Zn}, \mathrm{Cu}$, and $\mathrm{Mg}$, seemed to be imbedded in this $\mathrm{Mg}$-Si-rich phase. Most likely this phase is $\mathrm{Mg}_{2} \mathrm{Si}$, which is a common precipitate in AA6xxx alloys. ${ }^{5}$ However, no diffraction peak for $\mathrm{Mg}_{2} \mathrm{Si}$ could be obtained which demonstrates its low abundance. Additionally, nanometer-sized $\mathrm{Cu}$-rich precipitates were seen, as shown in Figure 7, which were most-likely $\mathrm{CuAl}_{2}$. In terms of number density, $\mathrm{Cu}-\mathrm{Al}$ compounds formed the majority of all precipitates and were homogeneously distributed over the entire microstructure. $\mathrm{CuAl}_{2}$ is a precipitation-hardening phase responsible for the high strength in $\mathrm{Al}$ alloys. However, most abundant intermetallic in terms of fraction was $\mathrm{Al}_{4.01} \mathrm{MnSi}_{0.74}$ in the AA6063-T5 studied.

In summary, XRD, EDX, and SEM data confirmed the presence of both micrometer- and nanometer-sized IMPs, and the chemical composition differed significantly between the intermetallics. Their electrochemical nobility may also differ, which will be assessed with the Volta potential data in the following.

SKFPM volta potential assessments.-Topography and corresponding Volta potential differences maps of the OP-S end-polished sample are shown in Figure 8. Precipitates were seen protruding from the surface by hundreds of nanometers. Most of them showed higher potentials and thus indicated higher electrochemical nobilities with respect to the matrix. There were both cathodic and anodic type of
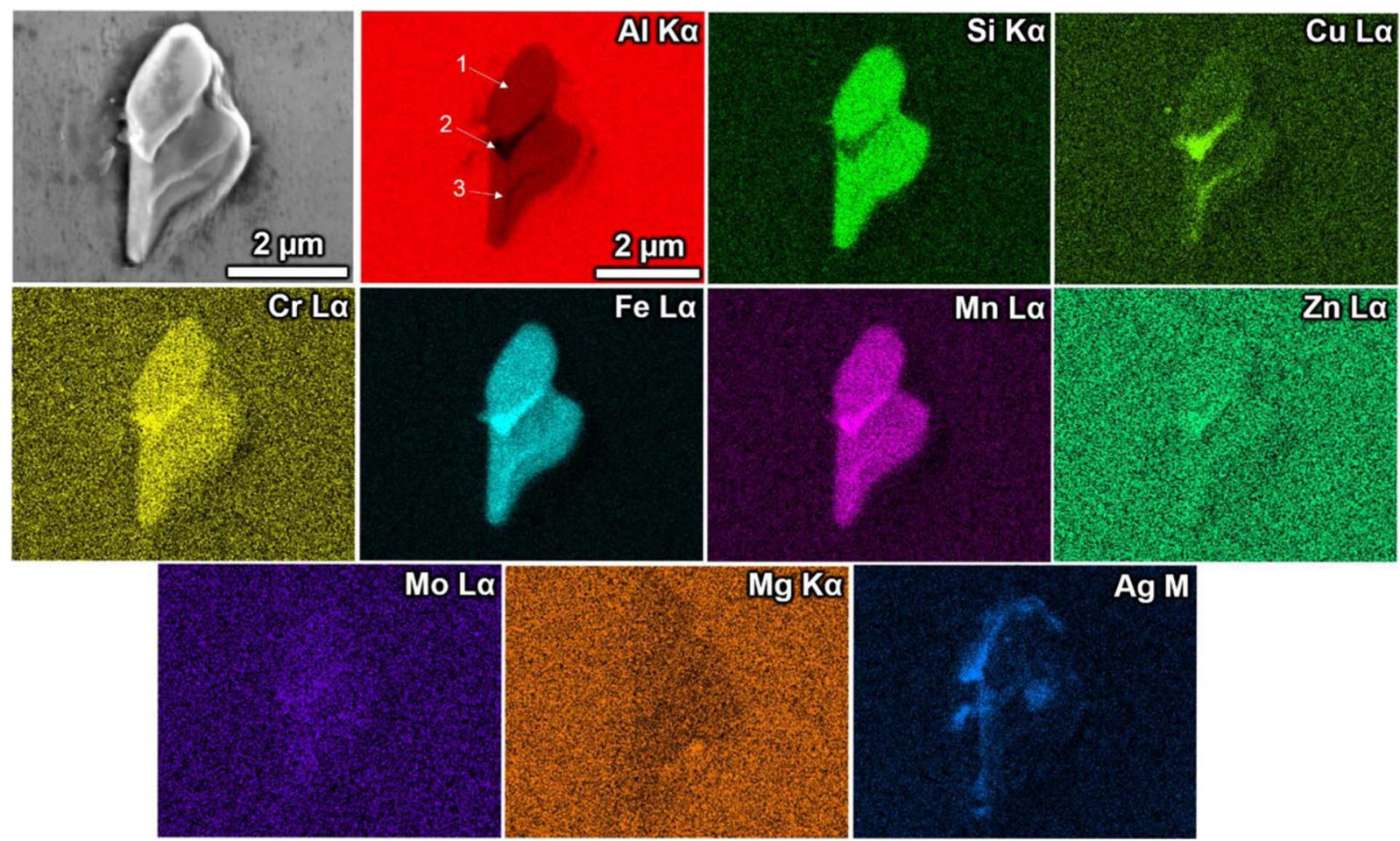

Figure 4. High-resolution EDX mapping of intermetallic particles attached to each other showing different chemical composition. The sample was OP-S endpolished. Chemical point analysis at the center of the particle revealed $75 \% \mathrm{Al}, 5 \% \mathrm{Si}, 1 \% \mathrm{Mn}, 1 \% \mathrm{Cu}, 0.5 \% \mathrm{Mg}$, and $17.5 \% \mathrm{Fe}$ (wt $\%$ ). The scale bar in $\mathrm{Al}$ map applies to all other chemical maps. 

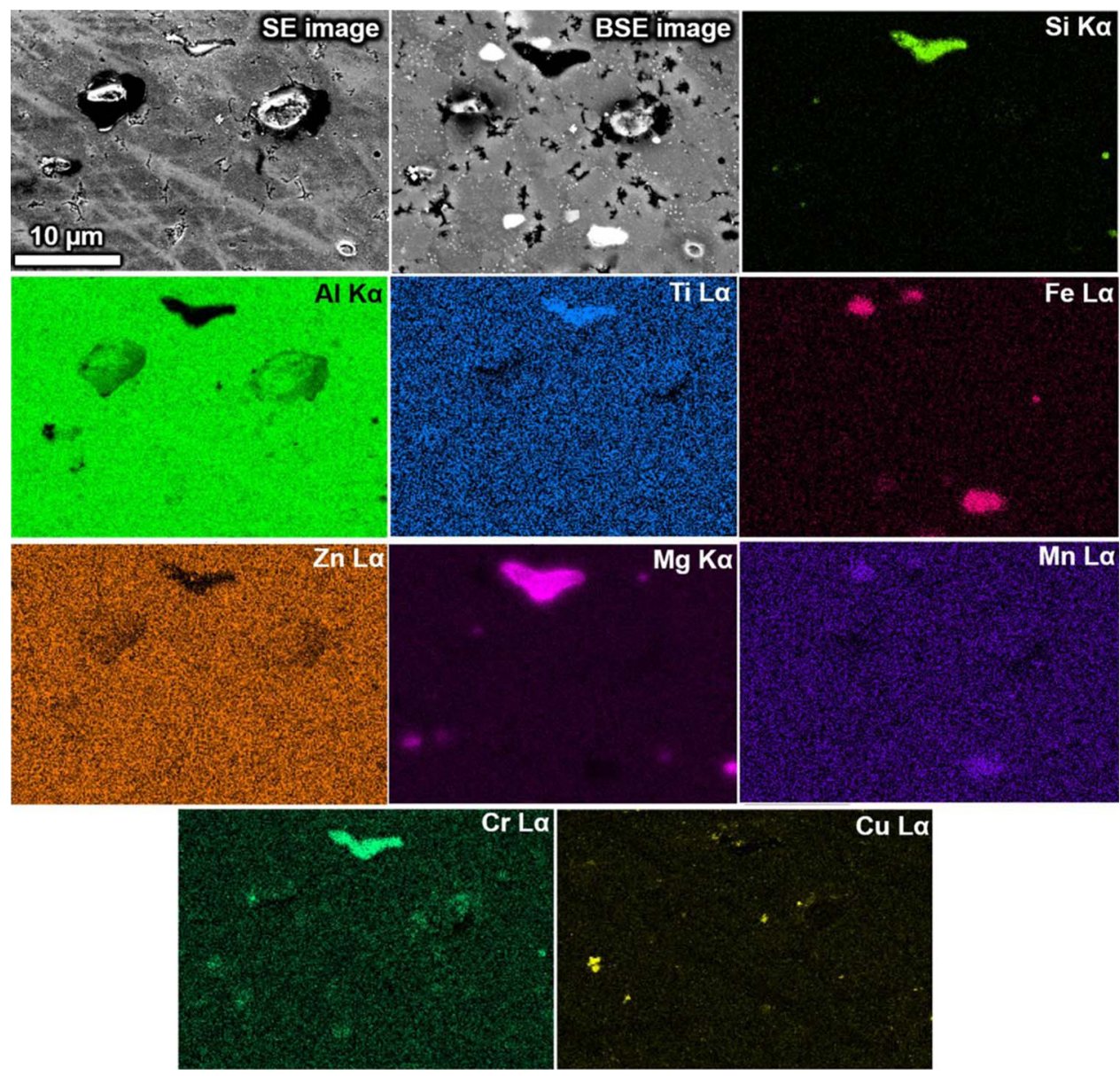

Figure 5. High-resolution EDX mapping of an electropolished sample. The scale bar in SE image (top left) applies to all images.

IMPs, and a large potential difference of up to $600 \mathrm{mV}$ between anodic and cathodic intermetallics were seen (Figure 8), suggesting high propensity for micro-galvanic corrosion. Furthermore, there were high Volta potential gradients of up to $\sim 300 \mathrm{mV} / \mu \mathrm{m}$ at interphase regions on adjacent sites to both anodic and cathodic particles. High potential gradients usually indicate high local corrosion activities. ${ }^{45-47,56}$

High Volta potential gradients existed at the interphase boundary regions. The width of the interphase boundary regions was defined as the distance between the point of the potential extreme of the particle and the point where the potential approached the matrix value (gradient levelled out), as shown in the potential vs. distance graph in Figure 8 . The results showed that in general the interphase boundary regions were larger for cathodic IMPs and smaller for anodic ones. In addition to the Volta potential difference between the particle and the alloy matrix, the width of the potential gradient zone (interphase boundary region) is also an important factor that can affect microgalvanic corrosion and has similarities to the sensitization zone. Such sites typically dissolve first in the corrosion process, ${ }^{45,46}$ and they have also been shown to accumulate most strain and microstructural mismatch in multi-phase alloys. ${ }^{56}$

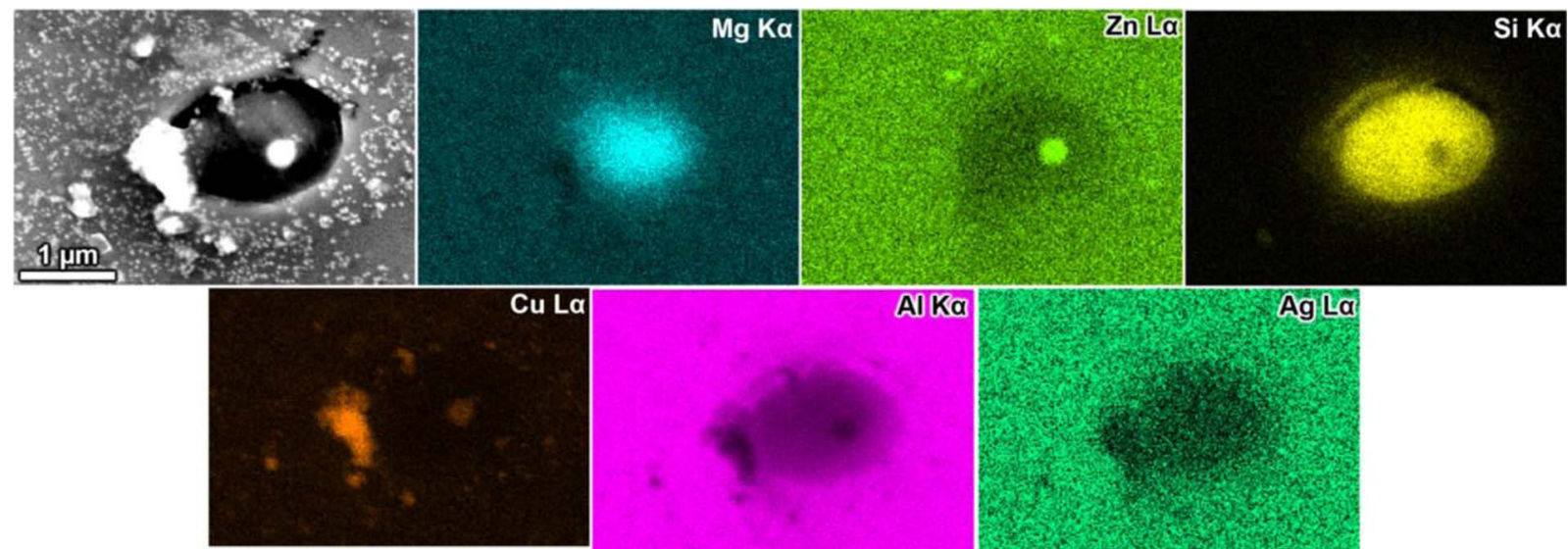

Figure 6. High-resolution EDX mapping of a region containing a Cu-Zn-rich particle entangled by an Al-Mg-Si-rich precipitate. The sample was electropolished. The scale bar in the SEM image (top left) applies to all images. 


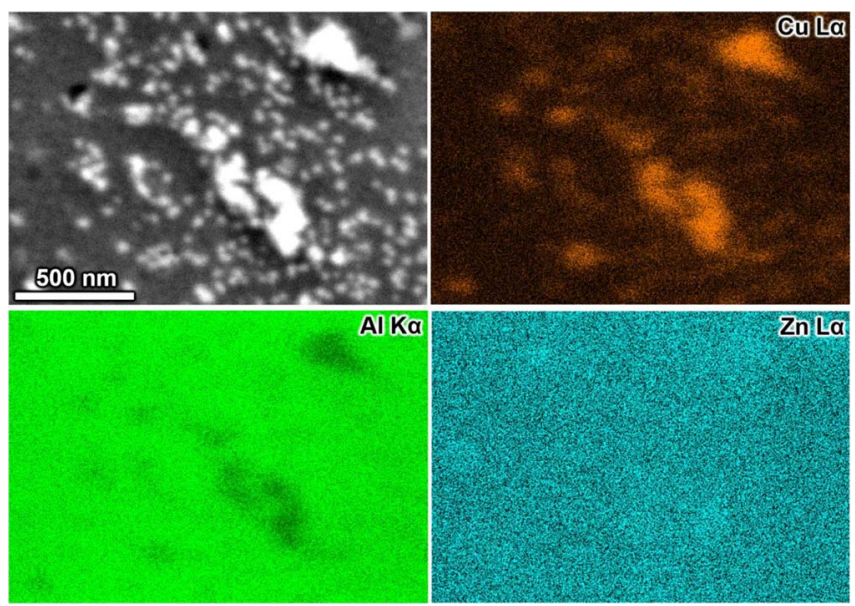

Figure 7. High-resolution EDX mapping of a region containing Cu-Zn-rich nanometer-sized particles. The sample was electropolished. The scale bar in the SEM image (top left) applies to all images.

High-resolution SKPFM mapping revealed sub-micron or nanometer-sized cathodic and anodic IMPs, as seen in Figure 9. A line profile over an anodic particle of ca. $250 \mathrm{~nm}$ in size (line 1) showed a Volta potential difference of $60-70 \mathrm{mV}$ with respect to the matrix, which usually is sufficient to initiate selective dissolution of such anodic sites. Volta potential differences of up to 190 $\mathrm{mV}$ between the IMPs and the Al matrix have previously been observed in the AA6060 alloy, and they showed high susceptibility to micro-galvanic activity. ${ }^{14}$ The same is expected for the AA6063-T5 alloy investigated in this work. The line profiles 2 and 3 in Figure 9 display the Volta potential variation across two cathodic particles. It should be noted that the cathodic particles, most likely of the $\mathrm{CuAl}_{2-}$ type, fell out during mechanical polishing and left some residues in their positions. Such regions can be considered as the interphase boundary region between the particle and the matrix. The Volta potential difference between the matrix and the center of the dimples varied between $170-230 \mathrm{mV}$ and indicated higher driving forces to microgalvanic activities in comparison to the small-sized anodic IMPs. The size of the IMP is one of the decisive parameters in micro-galvanic corrosion. ${ }^{15}$

Corrosion of AA6063-T5 in vanadate-containing solutions.Weight loss measurements.-The weight loss of the samples in 0.05 $\mathrm{M} \mathrm{NaCl}$ solution with and without $3 \mathrm{mM} \mathrm{NaVO}_{3}$ inhibitor measured versus exposure time is illustrated in Figure 10. As expected, in the chloride-containing electrolyte AA6063-T5 corrodes at a relatively high rate. In the solution containing $\mathrm{NaVO}_{3}$, the corrosion rate was significantly reduced. A dark-colored film on the surface of the sample, which was immersed in the inhibitor-containing electrolyte, was observed after 24 hours of exposure. The surface film became thicker after one week of exposure and had a yellow-orange color with some green-colored compounds in the areas of corrosion attack. The inhibition efficiency (IE) was calculated according to $0^{57}$

$$
\mathrm{IE}=\left[1-\left(\mathrm{WL} / \mathrm{WL}^{0}\right)\right] \times 100 \%
$$

where $\mathrm{WL}$ and $\mathrm{WL}^{0}$ are weight losses of the samples in solutions with and without the inhibitor, respectively. The calculated IE was $82 \%$ after 24 hours of exposure and decreased to $53 \%$ after 1000 hours. The calculated corrosion rate is an average value over the exposure period, assuming uniform corrosion on the whole surface. Its accuracy depends on the duration of the corrosion test, adsorption of corrosion products and/or inhibitor on the alloy's surface, and ease and completeness of their removal before weighing. Localized corrosion induced by the IMPs may give some error in the calculated corrosion rate. Nevertheless, the effect and the corrosion inhibition exerted by vanadates are clearly visible.

Potentiodynamic polarization measurements.-In all experiments, the OCP of the sample in the vanadate-containing solution was higher than that in the $\mathrm{NaCl}$ solution without inhibitor, indicating that vanadate retarded the kinetics of anodic dissolution of the alloy under open circuit conditions. Typical polarization curves obtained after 1 and 24 hours of exposure of the AA6063-T5 in $0.05 \mathrm{M} \mathrm{NaCl}$ solutions with and without the vanadate inhibitor are shown in Figure 11. Extracted electrochemical parameters from polarization curves were summarized in Table III. The large values of $b_{a}$ and $b_{c}$ were probably caused by the natural surface film formed before the polarization measurement, which may give some error in the calculated results. After 1 hour of exposure in the solution without inhibitor, active dissolution of the AA6063-T5 alloy occurred during anodic polarization, whereas
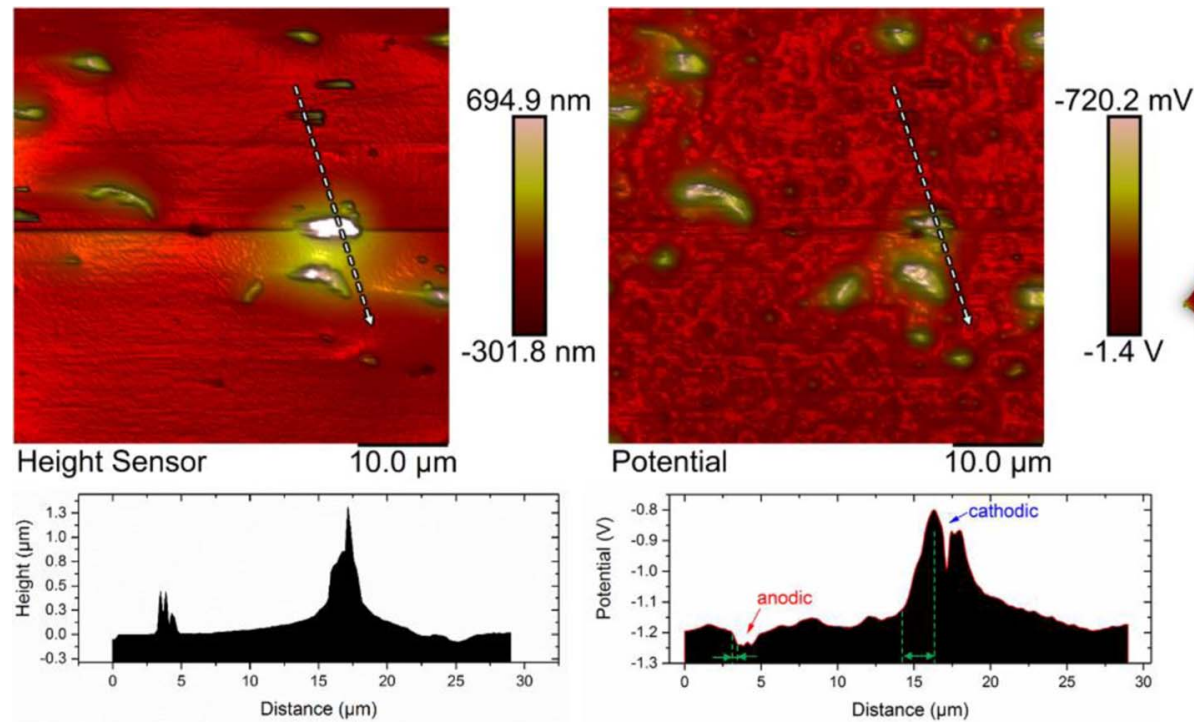

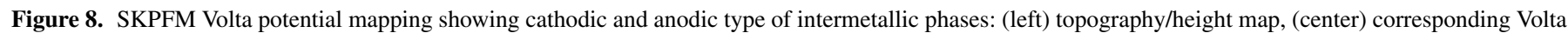

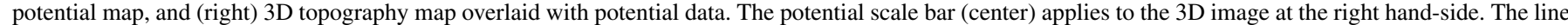

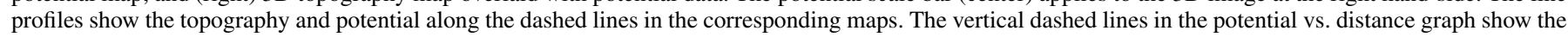
interphase region at an anodic and a cathodic particle. The sample was OP-S end-polished. 

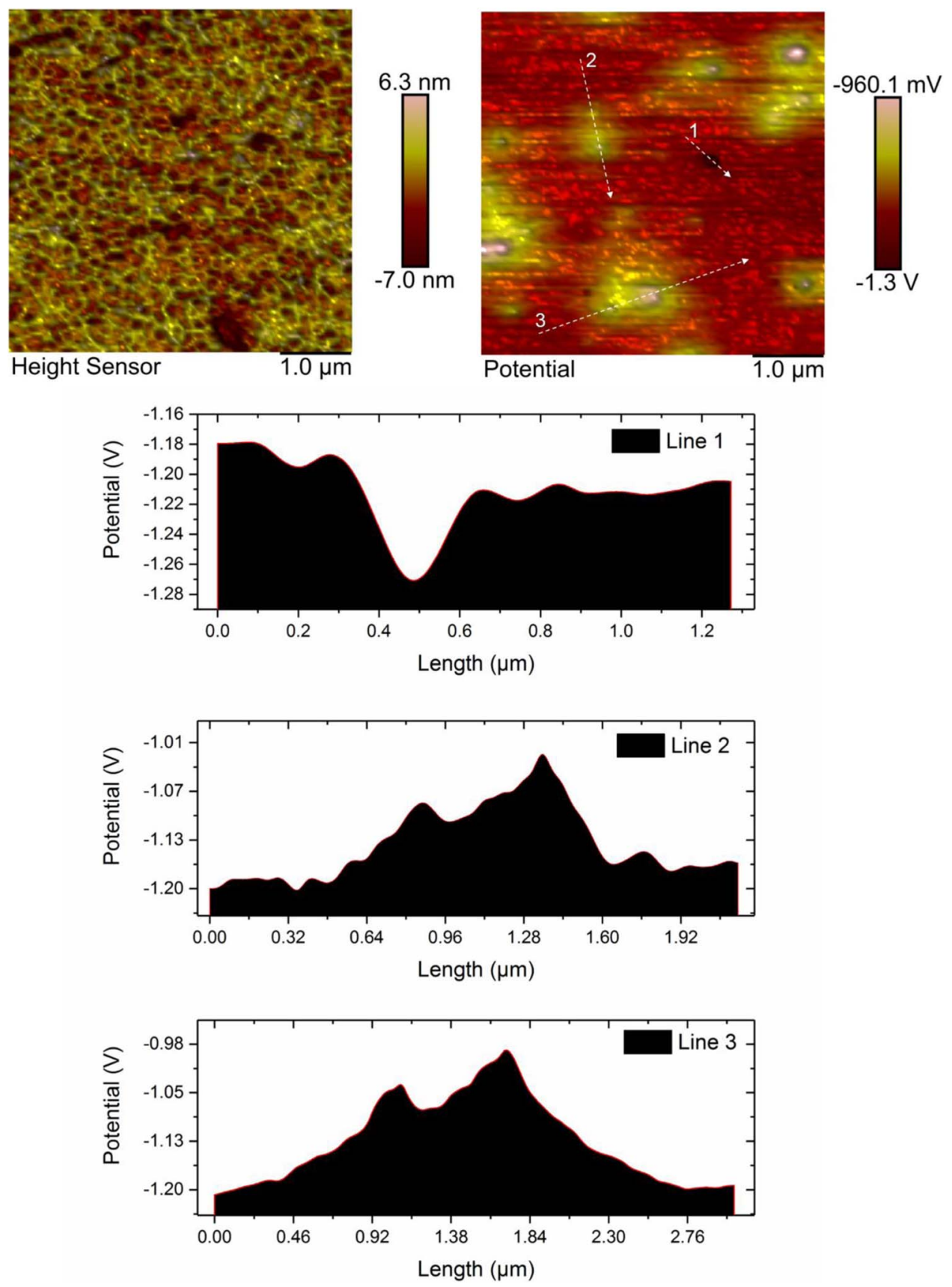

Figure 9. SKFPM Volta potential data showing nanometer-sized anodic and cathodic intermetallic phases: (top left) topography map, (top right) corresponding potential map, and line profiles of the lines shown in the potential map. The sample was OP-S end-polished.

the addition of $3 \mathrm{mM}$ of $\mathrm{NaVO}_{3}$ to the solution led to greatly decreased current density in the anodic branch. The breakdown potential, $E_{\mathrm{br}}$, was not reached in $3 \mathrm{mM} \mathrm{NaVO}_{3}$ solution within the measured polarization range. This suggests that the vanadate inhibitor increases the breakdown potential of IMPs in the alloy microstructure and decreases the incidence of circumferential attack around them, similar to observations made for AA2024. ${ }^{58}$ Suppression of the cathodic reaction in the vanadate-containing solutions was also observed from the cathodic branch of the polarization curves. After 24 hours of exposure in solution containing only $\mathrm{NaCl}$, the corrosion potential $\left(E_{\text {corr }}\right)$ decreased by $\approx 180 \mathrm{mV}$ and the corrosion current $i_{\text {corr }}$ increased significantly. In contrast, in the vanadate-containing solution only a slight decrease of $E_{\text {corr }}$ was observed and the corrosion current was even slightly lower after 24 hours than after 1 hour of exposure. After 24 hours, $E_{b r}$ was ca. $200 \mathrm{mV}$ higher in the vanadate-containing solution than in the solution without inhibitor. All these results indicate a high inhibition efficiency of the vanadate. In this case, IE values were calculated as

$$
\mathrm{IE}=\left[1-\left(i_{\text {corr }} / i_{\text {corr }}^{0}\right)\right] \times 100 \%
$$

where $i_{\text {corr }}^{0}$ and $i_{\text {corr }}$ are corrosion current densities in the absence and presence of the inhibitor, respectively. The corrosion current density was two orders of magnitude lower when the inhibitor was added into the solution. The calculated inhibition effectiveness was ca. $97 \%$ and $99 \%$ after 1 and 24 hours of exposure, respectively.

The obtained results are in agreement with reported observations for the AA6061 alloy, ${ }^{36}$ indicating that $\mathrm{NaVO}_{3}$ alters the electrochemical reactions involved in the corrosion process. The polarization curves as well as the extracted electrochemical parameters in Table III suggest that the vanadates provided mixed inhibition effects. The adsorbed vanadates on the alloy's surface seem to impede the anodic 


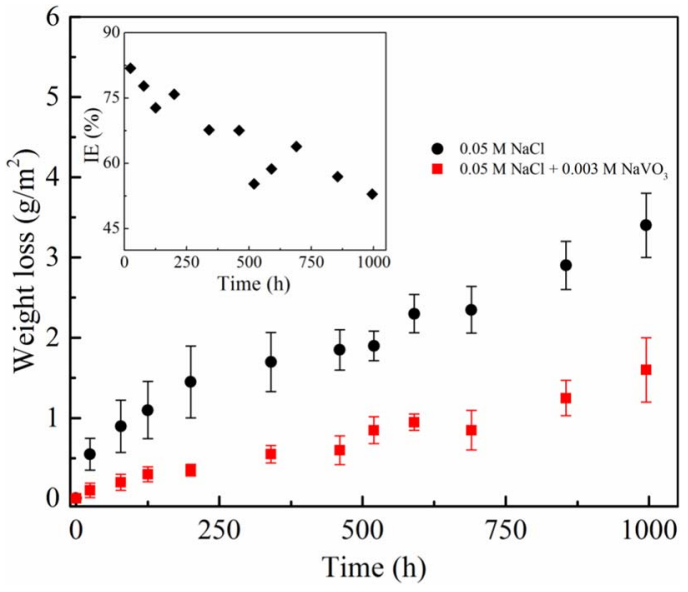

Figure 10. Weight loss vs. time in $0.05 \mathrm{M} \mathrm{NaCl}$ with and without $3 \mathrm{mM}$ $\mathrm{NaVO}_{3}$. The inserted graph shows the change of inhibition efficiency (IE) of vanadates vs. immersion time.

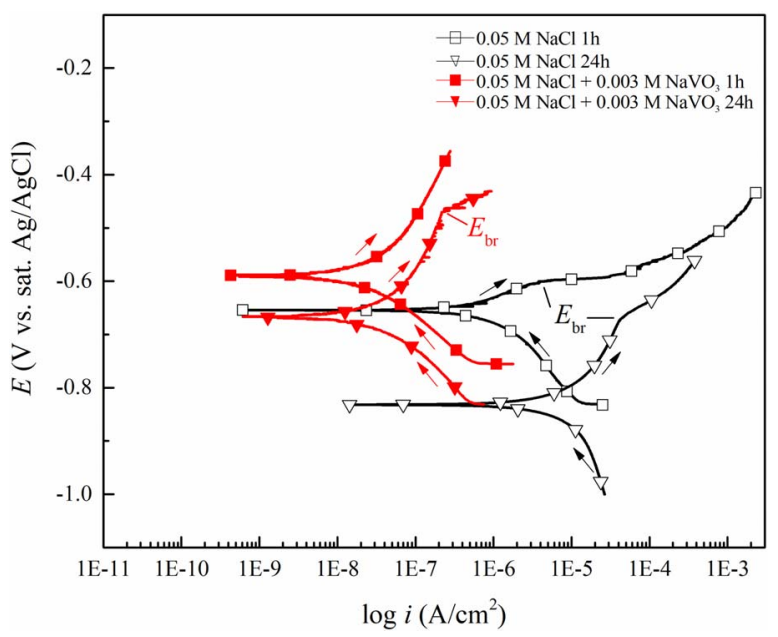

Figure 11. Potentiodynamic polarization curves obtained after 1 and 24 hours exposure in $0.05 \mathrm{M} \mathrm{NaCl}$ with and without $3 \mathrm{mM} \mathrm{NaVO}_{3}$. Arrows indicate the scan direction.

dissolution reaction occurring on active sites in the microstructure, such as $\mathrm{Mg}_{2} \mathrm{Si}$ particles and interphase boundary regions surrounding IMPs, and to retard the cathodic oxygen reduction reaction occurring on IMPs and passive regions of the alloy matrix. Hence, the vanadate inhibitor not only reduces the uniform corrosion rate, but also decreases the susceptibility to micro-galvanic corrosion of the material.

EIS analyses.-Nyquist plots of the EIS spectra obtained are shown in Figure 12. After 1 hour of exposure to $0.05 \mathrm{M} \mathrm{NaCl}$ solution, the spectrum showed a capacitive loop in the high and middle-frequency range and an inductive loop in the low-frequency range (graph inset in Figure 12). The inductive response is typically associated with

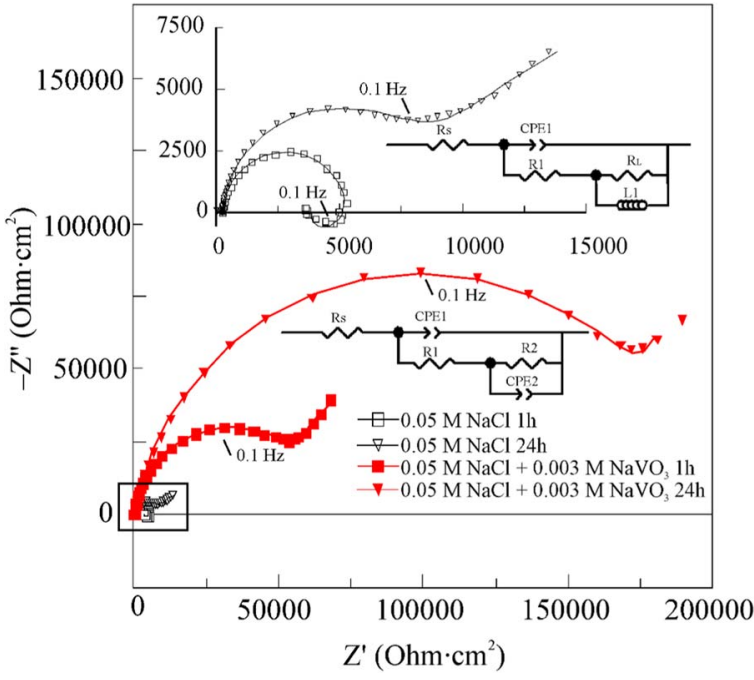

Figure 12. Nyquist EIS plots of the AA6063-T5 alloy in aqueous $0.05 \mathrm{M} \mathrm{NaCl}$ with and without $3 \mathrm{mM} \mathrm{NaVO}$ for 1 and 24 hours. The symbols correspond to experimental data and the lines are results of spectra fitting.

active anodic dissolution of $\mathrm{Al}$ alloys, which in this case may take place at defective sites in the native surface oxide layer such as $\mathrm{Mg}$ rich IMPs and interphase boundary regions surrounding IMPs. ${ }^{14,59}$ The inductive behavior could have originated from the relaxation phenomenon of intermediates, e.g. $\mathrm{Al}_{\text {ads }}^{+}, \mathrm{Al}_{\text {ads }}^{3+}, \mathrm{Mg}_{\text {ads }}^{2+}$, generated in the faradaic process involved in the localized corrosion of $\mathrm{Al}$ alloys. ${ }^{14,60}$ Such intermediates usually concentrate in the vicinity of the corroding sites, giving rise to the inductive response under AC perturbation.

The EIS spectra obtained after 24 hours of exposure in $0.05 \mathrm{M} \mathrm{NaCl}$ solution exhibited a capacitive loop in the high and middle-frequency range and a low-frequency diffusional tail. The capacitive loop was enlarged as compared to that obtained after 1 hour of exposure, which could be due to the formation of an oxide/hydroxide layer on the surface of the matrix and completion of selective $\mathrm{Mg}$ dissolution of Mg-rich IMPs, resulting in an increased polarization resistance. The disappearance of the low-frequency inductive loop could be a result of completion of active and selective dissolution of $\mathrm{Mg}$ from the surface layer, ${ }^{14}$ or a blocking effect by deposition of corrosion products at initially-active sites. ${ }^{16}$ The EIS spectra obtained in the vanadate-containing solution (Figure 12) also showed a capacitive loop in the high- and middle-frequency range and a low-frequency tail, and the capacitive loop was significantly larger, showing the inhibition effect of the vanadates.

Figure 12 also shows two equivalent circuits used for fitting of EIS spectra. In these circuits, $R_{\mathrm{S}}$ is the solution resistance, $R_{1}$ is the charge transfer resistance and $\mathrm{CPE}_{1}$ is a constant phase element for the electrochemical double layer, $L$ is the inductance, $R_{L}$ is the resistance of the adsorbed charged species, $R_{2}$ and $\mathrm{CPE}_{2}$ correspond to the resistance and constant phase element of the surface film, respectively. The constant phase element was used instead of pure capacitor in the spectra fitting to represent non-ideal capacitive response in real systems with a heterogeneous interface. The impedance of the CPE is

Table III. Electrochemical parameters extracted from potentiodynamic polarization measurements.

\begin{tabular}{|c|c|c|c|c|c|c|}
\hline Exposure time (h) & $E_{\text {corr }}(\mathrm{V})$ & $E_{\mathrm{br}}(\mathrm{V})$ & $i_{\text {corr }}\left(\mu \mathrm{A} / \mathrm{cm}^{2}\right)$ & $b_{\mathrm{a}}(\mathrm{mV} / \mathrm{dec})$ & $-b_{\mathrm{c}}(\mathrm{mV} / \mathrm{dec})$ & IE $(\%)$ \\
\hline \multicolumn{7}{|c|}{$0.05 \mathrm{M} \mathrm{NaCl}$} \\
\hline 1 & $-0.654 \pm 0.009$ & $-0.602 \pm 0.018$ & $(1.5 \pm 0.3) \times 10^{-6}$ & $499 \pm 31$ & $797 \pm 74$ & - \\
\hline 24 & $-0.832 \pm 0.034$ & $-0.673 \pm 0.021$ & $(9.5 \pm 0.7) \times 10^{-6}$ & $309 \pm 51$ & $216 \pm 42$ & - \\
\hline \multicolumn{7}{|c|}{$0.05 \mathrm{M} \mathrm{NaCl}+0.003 \mathrm{M} \mathrm{NaVO}_{3}$} \\
\hline 1 & $-0.586 \pm 0.012$ & - & $(7.7 \pm 0.2) \times 10^{-8}$ & $230 \pm 32$ & $269 \pm 41$ & 95 \\
\hline 24 & $-0.629 \pm 0.022$ & $-0.475 \pm 0.014$ & $(6.4 \pm 0.3) \times 10^{-8}$ & $288 \pm 12$ & $206 \pm 32$ & 99 \\
\hline
\end{tabular}


Table IV. Fitting data extracted from EIS measurements.

\begin{tabular}{|c|c|c|c|c|c|c|c|c|c|}
\hline Exposure time (h) & $R_{s}\left(\Omega \mathrm{cm}^{2}\right)$ & $R_{l}\left(\mathrm{k} \Omega \mathrm{cm}^{2}\right)$ & $Y_{l}\left(\Omega^{-1} \mathrm{~cm}^{-2} \mathrm{~s}^{n}\right)$ & $n_{1}$ & $R_{2}\left(\mathrm{k} \Omega \mathrm{cm}^{2}\right)$ & $Y_{2}\left(\Omega^{-1} \mathrm{~cm}^{-2} \mathrm{~s}^{n}\right)$ & $n_{2}$ & $L\left(\mathrm{kHcm}^{-2}\right)$ & $\mathrm{IE}(\%)$ \\
\hline \multicolumn{10}{|c|}{$0.05 \mathrm{M} \mathrm{NaCl}$} \\
\hline 1 & $233 \pm 20$ & $3.6 \pm 0.3$ & $10 \pm 1$ & $0.97 \pm 0.02$ & $1.6 \pm 0.4$ & - & - & $1.2 \pm 0.2$ & - \\
\hline 24 & $222 \pm 15$ & $9.5 \pm 0.4$ & $47 \pm 11$ & $0.95 \pm 0.02$ & $28 \pm 0.1$ & $670 \pm 240$ & $0.69 \pm 0.10$ & - & - \\
\hline \multicolumn{10}{|c|}{$0.05 \mathrm{M} \mathrm{NaCl}+0.003 \mathrm{M} \mathrm{NaVO}_{3}$} \\
\hline 1 & $198 \pm 17$ & $66 \pm 1$ & $21 \pm 8$ & $0.94 \pm 0.03$ & $82 \pm 1$ & $510 \pm 210$ & $1.00 \pm 0$ & - & 99 \\
\hline 24 & $230 \pm 28$ & $190 \pm 10$ & $5.5 \pm 3.2$ & $0.88 \pm 0.08$ & $160 \pm 10$ & $5.7 \pm 2.1$ & $0.98 \pm 0.01$ & - & 95 \\
\hline
\end{tabular}

given by

$$
Z_{C P E}=1 /\left[Y(j \omega)^{n}\right]
$$

where $Y$ is a constant and the exponent $n$ is obtained from the data fitting. Depending on $n$ value, Equation 3 can describe a pure capacitance $(n=1)$, a Warburg impedance $(n \approx 0.5)$, and an ideal resistance $(n=0) .{ }^{61}$ The fit parameter $n$ is often related to the degree of heterogeneity of the interface/surface film. ${ }^{14}$ The fitting results are summarized in Table IV. For the two CPE elements, $\mathrm{CPE}_{1}$ and $\mathrm{CPE}_{2}$, both their constant $\left(Y_{1}\right.$ and $\left.Y_{2}\right)$ and the exponent $\left(n_{1}\right.$ and $\left.n_{2}\right)$ are given in Table IV. Because of a small tail at low frequencies, the fitting data corresponding to low frequency response are less certain. From the EIS data, IE was calculated through the change in the charge transfer resistance

$$
\mathrm{IE}=\left[1-\left(R_{1}^{0} / R_{1}\right)\right] \times 100 \%
$$

where $R_{1}$ and $R_{1}^{0}$ are the charge transfer resistance with and without inhibitor, respectively. For the samples exposed to $0.05 \mathrm{M} \mathrm{NaCl}$ solution, the charge transfer and surface film resistance slightly increased with exposure time, which may be explained by the formation of a surface film of corrosion products. The increase of the CPE constant $Y_{1}$ resulted from the increase of the surface roughness due to corrosion processes. ${ }^{14,62}$ In the vanadate-containing solution, the increase in charge transfer and surface film resistance were more pronounced than in the solution without inhibitor, and the CPE constant of both the double layer and surface film decreased significantly from 1 to 24 hours. The adsorption and deposition of the inhibitor and corrosion products at initially active sites on the alloy surface and a consequent blocking effect led to the changes in the measured resistance and the CPE constant values. These results suggest the formation and growth of a protective surface film consisting of inhibitor and corrosion products, which resulted in a significant improvement in the corrosion resistance of the alloy by the vanadate inhibitor.

The IE values calculated from the EIS data were $99 \%$ and $95 \%$ after 1 and 24 hours of exposures, respectively. Strictly speaking, since two different equivalent circuits were used for the fitting of EIS spectra, the data obtained are not directly comparable, so caution should be taken in the comparison of the quantitative data and IE calculations. This is also seen by the slightly varying IE-values obtained with different methods in this study. For instance after 24 hour, the average IEvalue, determined by the weight-loss method, was $82 \%$, whereas an instantaneous value of $99 \%$ was calculated from the polarization curve and a value of $95 \%$ was obtained from analysis of the EIS spectra. Despite of this slight difference in IE values, the results show high inhibition efficiency within 1 day of exposure. Long-term weight loss measurements indicate a decrease of IE with exposure time.

Mechanism of corrosion inhibition by vanadates.-Corrosion inhibition is provided mainly by tetrahedrally coordinated $\mathrm{V}^{+5}$ aqueous vanadates, ${ }^{7,24,25,61}$ and therefore these species are important at the initial inhibition stage. XRD and SEM/EDX results showed that numerous $\mathrm{Fe}$ - and $\mathrm{Cu}$-rich cathodic IMPs are present in the microstructure of the alloy AA6063-T5. As reported for alloy AA2024, interactions of vanadates with $\mathrm{Cu}$-rich cathodic IMPs play vital role in the inhibition mechanism. ${ }^{25,28,29,33}$ IMPs in the microstructure can induce micro-galvanic corrosion, and therefore, the inhibition effect may likely be associated with interactions of the vanadates with cathodic
IMPs. Our electrochemical data suggest that the vanadates can provide a mixed inhibition impeding both anodic and cathodic reactions, which was not typical for AA2024, where mostly cathodic inhibition was observed. ${ }^{25,28,33}$ On the alloy surface, Al is spontaneously oxidized to form a thin oxide film. However, the presence of large IMPs and lack of a protective oxide film on the boundary regions surrounding the IMPs may trigger localized corrosion in the boundary regions, ${ }^{43,45}$ leading to extensive corrosion attack. Adsorption of vanadates on cathodic IMPs usually limits oxygen adsorption on such sites and, thus, impedes the oxygen reduction reaction that is the dominant cathodic reaction in near-neutral solutions that was observed on the polarization curves. Being strong oxidants, adsorbed $\mathrm{V}^{+5}$ species are spontaneously reduced to $\mathrm{V}^{+4}$ species on the surface, especially in local acidic sites..$^{28,58}$ On the other hand, the vanadates inhibitor could also impede anodic dissolution reactions occurring on the active sites, such as Mg-rich particles and interphase boundary regions surrounding large cathodic IMPs.

\section{Conclusions}

In this paper, a comprehensive microstructure characterization including local Volta potential assessments of both anodic and cathodic type of intermetallic phases in aluminum alloy AA6063-T5 was carried out and correlated with potentiodynamic polarization, electrochemical impedance spectroscopy, and weight loss measurements to assess the corrosion inhibitor efficiency of sodium metavanadate. The following conclusions can be drawn:

1. XRD and SEM/EDX revealed the presence of micrometer-sized $\mathrm{Al}_{4.01} \mathrm{MnSi}_{0.74}, \mathrm{Al}_{1.69} \mathrm{Mg}_{4} \mathrm{Zn}_{2.31}$, and $\mathrm{FeAl}_{3}$ intermetallic phases and nanometer-sized $\mathrm{CuAl}_{2}, \mathrm{Mg}_{2} \mathrm{Si}$, and $\mathrm{ZnAl}_{2}$ type of IMPs in the microstructure.

2. SKPFM measurements showed Volta potential differences of up to $600 \mathrm{mV}$ within the microstructure indicating a high susceptibility to micro-galvanic corrosion between microstructure constituents in some environments. Most intermetallic phases were seen to have intrinsic cathodic character, whereas some nanometer-sized $\mathrm{Mg}_{2} \mathrm{Si}$ particles were seen to be electrochemically anodic nature.

3. Addition of $3 \mathrm{mM} \mathrm{NaVO}_{3}$ in aqueous $0.05 \mathrm{M} \mathrm{NaCl}$ solution resulted in a significant decrease in the corrosion rate of AA6063T5. $\mathrm{NaVO}_{3}$ provides mixed corrosion inhibition effects by the formation of an adsorbed surface layer of vanadates, resulting in a decrease of both the oxygen reduction reaction occurring at cathodic regions (cathodic intermetallics) and active metal dissolution at anodic sites (e.g. $\mathrm{Mg}_{2} \mathrm{Si}$ and interphase boundary regions).

4. The inhibition efficiency measured by electrochemical methods was $>95 \%$ within 1 day of exposure. The weight loss measurements show that the inhibition efficiency decreases after longterm exposure (hundreds of hours).

\section{Acknowledgments}

The authors at Belarusian State Technological University greatly acknowledge the financial support to this study by The Ministry of Education of the Republic of Belarus under the grant no. 20161135. Dmitry Kharitonov is grateful for a scholarship from the Swedish Institute within the Visby programme. The authors thank Taspo Radi- 
ators, Minsk, Belarus, for providing the material, and are also grateful for Swerea KIMAB, Stockholm, Sweden, for granting access to their electron microscopy facility.

\section{ORCID}

Dmitry S. Kharitonov (D) https://orcid.org/0000-0003-2071-3975

Cem Ornek (D) https://orcid.org/0000-0002-3029-6493

Jinshan Pan (1) https://orcid.org/0000-0002-4431-0671

\section{References}

1. J. R. Davis, in Alloying: Understanding the Basics, J. R. Davis, editor, p. 351, ASM International, Ohio (2001).

2. G. M. Scamans, N. Birbilis, and R. G. Buchheit, in Shreir's Corrosion, T. J. Richardson, Editor, Vol. 2, p. 1974, Elsevier, Amsterdam (2010).

3. K. A. Yasakau, J. Tedim, M. L. Zheludkevich, and M. G. S. Ferreira, in Handbook of Smart Coatings for Materials Protection, A. S. Hamdy, Editor, p. 224 (2014).

4. W. Zhu, W. Li, S. Mu, N. Fu, and Z. Liao, Appl. Surf. Sci., 405, 157 (2017).

5. F. Eckermann, T. Suter, P. J. Uggowitzer, A. Afseth, and P. Schmutz, Electrochim. Acta, 54, 844 (2008).

6. S. Nandy, K. Kumar Ray, and D. Das, Mater. Sci. Eng., A, 644, 413 (2015).

7. F. L. Zeng, Z. L. Wei, J. F. Li, C. X. Li, X. Tan, Z. Zhang, and Z. Q. Zheng, T Nonferr Metal Soc, 21, 2559 (2011).

8. O. Guseva, J. A. DeRose, and P. Schmutz, Electrochim. Acta, 88, 821 (2013).

9. O. Lopez-Garrity and G. S. Frankel, J. Electrochem. Soc., 161, C95 (2013).

10. A. Davoodi, J. Pan, C. Leygraf, and S. Norgren, Electrochim. Acta, 52, 7697 (2007).

11. A. Davoodi, J. Pan, C. Leygraf, and S. Norgren, J. Electrochem. Soc., 155, C211 (2008).

12. A. Davoodi, J. Pan, C. Leygraf, R. Parvizi, and S. Norgren, Mater. Corros., 64, 195 (2013).

13. F. Zhang, J. Evertsson, F. Bertram, L. Rullik, F. Carla, M. Långberg, E. Lundgren, and J. Pan, Electrochim. Acta, 241, 299 (2017).

14. F. Zhang, J. O. Nilsson, and J. S. Pan, J. Electrochem. Soc., 163, C609 (2016).

15. L. Yin, Y. Jin, C. Leygraf, N. Birbilis, and J. Pan, J. Electrochem. Soc., 164, C75 (2017).

16. L. T. Yin, Y. Jin, C. Leygraf, and J. S. Pan, Electrochim. Acta, 192, 310 (2016).

17. M. W. Kendig and R. G. Buchheit, Corrosion, 59, 379 (2003).

18. P. Pokorny, P. Tej, and P. Szelag, Metalurgija, 55, 253 (2016).

19. R. L. Twite and G. P. Bierwagen, Prog. Org. Coat., 33, 91 (1998).

20. R. L. Cook and S. R. Taylor, Corrosion, 56, 321 (2000).

21. X. B. Chen, N. Birbilis, and T. B. Abbott, Corrosion, 67 (2011).

22. P. Coloma, U. Izagirre, Y. Belaustegi, J. B. Jorcin, F. J. Cano, and N. Lapena, Appl. Surf. Sci., 345, 24 (2015).

23. Y. B. Gao, J. Hu, J. Zuo, Q. Liu, H. Zhang, S. G. Dong, R. G. Du, and C. J. Lin, J. Electrochem. Soc., 162, C555 (2015).

24. S. B. Madden and J. R. Scully, J. Electrochem. Soc., 161, C162 (2014).

25. K. D. Ralston, S. Chrisanti, T. L. Young, and R. G. Buchheit, J. Electrochem. Soc., 155, C350 (2008).

26. Y. T. Tan, S. L. Wijesinghe, and D. J. Blackwood, J. Electrochem. Soc., 163, C649 (2016).
27. H. Guan and R. G. Buchheit, Corrosion, 60, 284 (2004)

28. B. L. Hurley, S. Qiu, and R. G. Buchheit, J. Electrochem. Soc., 158, C125 (2011).

29. M. Iannuzzi and G. S. Frankel, Corros. Sci., 49, 2371 (2007).

30. M. Iannuzzi and G. S. Frankel, Corrosion, 63, 672 (2007).

31. M. Iannuzzi, J. Kovac, and G. S. Frankel, Electrochim. Acta, 52, 4032 (2007).

32. M. Iannuzzi, T. Young, and G. S. Frankel, J. Electrochem. Soc., 153, B533 (2006).

33. J. Li, B. Hurley, and R. Buchheit, J. Electrochem. Soc., 162, C219 (2015).

34. A. S. Hamdy, I. Doench, and H. Mohwald, Thin Solid Films, 520, 1668 (2011).

35. K. H. Yang, M. D. Ger, W. H. Hwu, Y. Sung, and Y. C. Liu, Mater. Chem. Phys., 101, 480 (2007).

36. K. D. Ralston and R. G. Buchheit, ECS Electrochem. Lett., 2, C35 (2013).

37. D. S. Kharitonov, I. I. Kurilo, and I. M. Zharskii, Sviridov Readings, 12, 117 (2016).

38. J. Seong, G. S. Frankel, and N. Sridhar, J. Electrochem. Soc., 162, C449 (2015).

39. D. S. Kharitonov, I. I. Kurilo, and I. M. Zharskii, Russ. J. Appl. Chem., 90, 1089 (2017).

40. D. S. Kharitonov, I. I. Kurilo, A. Wrzesinska, and I. M. Zharskii, Mat.-wiss. $u$. Werkstofftech, 28, 646 (2017).

41. A. K. Gupta, P. H. Marois, and D. J. Lloyd, Mater. Charact., 37, 61 (1996).

42. G. Mrówka-Nowotnik, J. Sieniawski, and M. Wierzbiñska, Arch. Mat. Sci. Eng., 28, 69 (2007).

43. N. Birbilis and R. G. Buchheit, J. Electrochem. Soc., 152, B140 (2005).

44. K. H. Anantha, C. Örnek, S. Ejnermark, A. Medvedeva, J. Sjöström, and J. Pan, J. Electrochem. Soc., 164, C85 (2017).

45. C. Örnek and D. L. Engelberg, Corros. Sci., 99, 164 (2015).

46. C. Örnek and D. L. Engelberg, J. Mater. Sci., 51, 1931 (2016).

47. C. Örnek, J. Walton, T. Hashimoto, T. L. Landwein, S. B. Luon, and D. L. Engelberg, J. Electrochem. Soc., 164, 207 (2017).

48. P. Schmutz and G. S. Frankel, J. Electrochem. Soc., 145, 2285 (1998).

49. V. Guillaumin, P. Schmutz, and G. S. Frankel, J. Electrochem. Soc., 148, B163 (2001).

50. M. Iannuzzi, K. L. Vasanth, and G. S. Frankel, J. Electrochem. Soc., 164, C488 (2017).

51. Y. Jin, M. Liu, C. Zhang, C. Leygraf, L. Wen, and J. Pan, J. Electrochem. Soc., 164, C465 (2017).

52. J. R. Davis, Corrosion of Aluminum and Aluminum Alloys, p. 313, ASM International, Ohio (1999).

53. ISO 8407-2009: Corrosion of metals and alloys: Removal of corrosion products from corrosion test specimens.

54. I. Polmer, Light Alloys - From Traditional Alloys to Nanocrystals, p. 416, Elsiever, Oxford (2005).

55. W. Bergmann, Werkstofftechnik 1, p. 360, Carl Hanser Verlag, Munich (2008).

56. C. Örnek and D. L. Engelberg, J. Strain Anal. Eng. Des., 51, 207 (2016).

57. M. A. Amin, S. S. A. EI-Rehim, E. El-Sherbini, O. A. Hazzazi, and M. N. Abbas, Corros. Sci., 51, 658 (2009).

58. K. D. Ralston, T. L. Young, and R. G. Buchheit, J. Electrochem. Soc., 156, C135 (2009).

59. P. Marcus and J. Oudar, Corrosion Mechanisms in Theory and Practice, p. 641, M. Dekker, New York (1995).

60. M. Keddam, C. Kuntz, H. Takenouti, D. Schustert, and D. Zuili, Electrochim. Acta, 42, 87 (1997).

61. R. Orozco-Cruz, R. Galvan-Martinez, E. A. Martínez, and I. Fernandez-Gómez, ECS Transactions, 29, 73 (2010).

62. J. Wysocka, S. Krakowiak, J. Ryl, and K. Darowicki, J. Electroanal. Chem., 778, 126 (2016). 